\title{
The ameliorative effect of black soybean and purple sweet potato to improve sperm quality through suppressing reactive oxygen species (ROS) in type 2 diabetes mellitus rat (Rattus novergicus)
}

\author{
Abdul Gofur ${ }^{\mathrm{a}, *}$, Agung Witjoro ${ }^{\mathrm{a}}$, Erni Widya Ningtiyas ${ }^{\mathrm{a}}$, Evi Setyowati ${ }^{\mathrm{a}}$, \\ Siti Aminatul Mukharromah ${ }^{\mathrm{a}}$, Suhartini ${ }^{\mathrm{a}}$, Mochammad Fitri Atho'illah ${ }^{\mathrm{b}}$, Sri Rahayu Lestari ${ }^{\mathrm{a}}$ \\ a Department of Biology, Faculty of Mathematic and Natural Science, Universitas Negeri Malang, Malang, \\ Indonesia 65145 \\ b Department of Biology, Faculty of Mathematic and Natural Science, Brawijaya University, Malang, \\ Indonesia 65145
}

*Corresponding author, e-mail: abdul.gofur.fmipa@um.ac.id

Received 10 May 2018

Accepted 31 Oct 2018

\begin{abstract}
Overproduction of reactive oxygen species (ROS) will promote oxidative damage and can induce reproductive disorder. A therapeutic strategy to reduce effects of reproductive disorder is by maintaining the balance between ROS and antioxidants. Black soybean (BSB) contains phenolic compounds and has a greater antioxidant capacity than yellow soybean. Purple sweet potato (PSP) also has antioxidant capacity, due to the presence of anthocyanin, but is low in protein. The combination of BSB and PSP is expected to limit symptoms of reproductive disorder through decreasing ROS levels, enhancing testosterone production, and improve sperm quality. The results of this study indicate that the combination of PSP and BSB could restore blood glucose levels, improve seminiferous tubules diameter, decrease ROS production, and improve testosterone and sperm quality. A ratio of BSB to PSP of 2:2 and 3:1 were effective to improve symptoms of reproductive disorder in the type 2 diabetes mellitus (T2DM) rat model.
\end{abstract}

KEYWORDS: anthocyanin, free radical, isoflavone, male reproductive

\section{INTRODUCTION}

The number of people suffering from diabetes mellitus (DM) in the world is expected to increase each year with an estimated 642 million patients by 2040 . Indonesia has the sixth highest number of DM cases in the world, with 16.2 million people expected to suffer from DM by $2040^{1}$. The number of people suffering from DM is predicted to increase by $50 \%$ in the next 20 years, causing as significant global economic challenge for the health service systems world-wide ${ }^{2}$.

DM is included in the group of metabolic diseases that are closely related to hyperglycaemia. Defects in insulin secretion, insulin action, or both in this disorder can result in the development of chronic low-grade inflammation ${ }^{3}$. Type 2 DM (T2DM) dominates all DM cases in the world accounting for $90-95 \%$ of cases ${ }^{4}$. Approximately $90 \%$ of male DM patients have sexual dysfunction such as decreased libido, impotence, decreased testicular weight, reduced number, motility, and viability of sperm, and increased incidence of sperm abnormalities ${ }^{5}$. In addition, infertility has been reported in around $35 \%$ of $\mathrm{T}_{2} \mathrm{DM}^{6}$.

Free radicals, especially reactive oxygen species (ROS), are products of normal metabolism in mitochondria $^{7}$. In hyperglycaemia conditions, the production of ROS will increase. In contrast, the production of antioxidant content will decrease under this condition ${ }^{8}$. The increasing production of ROS will increase oxidative stress and tissue damage and has the potential to decrease the sperm quality and function ${ }^{9}$. Spermatozoa are very vulnerable to damage caused from oxidative stress due to the high content of polyunsaturated fatty acids (PUFA) in their plasma membrane and low antioxidant enzyme activity in the cytoplasm ${ }^{5}$. The negative impacts of ROS on the sperm quality have been well established ${ }^{10}$ suggesting that balancing elevated ROS levels in hyperglycaemia conditions by the addition of the antioxidants may have beneficial effects. 
Purple sweet potato (PSP) is an agricultural product that is rich in carbohydrate, fibre, and minerals ${ }^{11}$. In addition, PSP has a high content of anthocyanin that can function as a strong scavenger of free radicals ${ }^{12}$. Sweet potato has also been found to exhibit an anti-hyperglycaemic effect in diabetic animal models ${ }^{13}$. Kawi sweet potato is a local variety planted in the Kawi Mountains, Malang and contains $100-220 \mathrm{mg} / 100 \mathrm{~g}$ anthocyanin ${ }^{14}$. Recent evidence suggests that sweet potato consumption may improve sperm quality in male rats ${ }^{15}$. However, beneficial effects of sweet potato on DM has not been examined. While sweet potato is a source of complex carbohydrates, it is low in protein and its use would require combination with a high protein food such as black soybean (BSB).

BSB is extensively used in China as a dietary protein source and is thought to prevent many kinds of diseases due to the large content of antioxidants both in the hull and full seed ${ }^{16}$. Unfortunately, in Indonesia the black soybean is typically only used as a raw material for soy sauce. The high content of phenolic compounds in BSB is thought to provide the improved antioxidant capacity compared to that seen in yellow soybean ${ }^{17}$. One of the major phenolic compounds present in BSB is anthocyanin cyanidin3-O- $\beta$-glucoside $(\mathrm{C} 3 \mathrm{G})$ which can reduce free radicals ${ }^{18}$.

Our previous analysis indicated that the processing by-product of BSB could restore the quality of spermatozoa in mice fed a high-fat diet ${ }^{19}$. However, the beneficial effect on the male reproduction system from a combination of sweet potato and high antioxidant-BSB has not been examined in detailed. The antioxidant content in PSP and BSB is expected and can work together to decrease the accumulation of free radicals, improving the quality and function of spermatozoa in the T2DM rat model.

\section{MATERIALS AND METHODS}

\section{Reagents}

The chemical materials used included streptozotocin (41910012-3: Bioworld), glibenclamide (Indofarma, Bekasi, Indonesia), c-ROS polyclonal antibody (bs-2504R: BIOSS), testosterone (E-EL0072: Elabscience), goat anti-Rat IgG-FITC (sc2011: Santa Cruz).

\section{Preparation of BSB and PSP}

PSPs were obtained from a plantation of purple sweet potato in the Kawi Mountain, Malang Regency. The BSB var. Detam-1 was purchased from
BALITKABI, Malang Regency. The production of the flour of PSP and BSB was conducted in Materia Medika Hall, Batu City. PSPs that had been washed were cut into small and thin pieces and then dried. After drying they were ground into flour. The BSBs were washed, dried, and ground into flour.

\section{Animals}

Four week-old male rats (Rattus novergicus), of the Wistar strain, with a weight between 50 and $75 \mathrm{~g}$ were obtained from Malang Murine Farm, Singosari, Malang Regency. The rats were caged individually and maintained with $12 \mathrm{~h}$ of light/dark cycle at a temperature of $25 \pm 2{ }^{\circ} \mathrm{C}$. The rats were adapted for one week prior to the experimental trial. Feed and drink were given ad libitum. After seven days of adaptation, rats were randomly divided into eight groups. All procedures for maintaining and treating rats followed the procedures from the Research Ethics Commission of Brawijaya University, Malang, registration number 878-KEP-UB.

\section{Experimental design}

The T2DM rat model was generated by giving a high calorie-feed and streptozotocin (STZ) injections. The T2DM groups were fed $74 \%$ carbohydrate, $6 \%$ fat, $20 \%$ protein, vitamins, minerals and $1 \%$ fibre for diet (PT Phokphand, Indonesia). The normal group was fed $63 \%$ carbohydrate, $3 \%$ fat, $13 \%$ protein, $21 \%$ vitamin and mineral for diet (PT Comfeed, Indonesia) ${ }^{20}$. STZ injections were done intraperitoneally to fasting rats using a low dose $(30 \mathrm{mg} / \mathrm{kg}$ body weight (BW) diluted in citrate buffer, $\mathrm{pH}$ 4.5) for four consecutive days in one week $^{21}$. Rats with a blood glucose level of greater or equal to $200 \mathrm{mg} / \mathrm{dl}$ after seven days of STZ injection were categorized as DM and divided in the treatment groups. Rats were randomly divided into eight groups $(n=5)$ as follows: healthy/normal rats $(\mathrm{N}), \mathrm{T} 2 \mathrm{DM}$ rats without treatment (DM), T2DM rats given $0.6 \mathrm{mg} / \mathrm{kg} \mathrm{BW}$ glibenclamide $(\mathrm{DM}+\mathrm{Glb})$, DMT 2 rats given black soybean diet (DM + BSB), T2DM rats given diet purple sweet potato (DM + PSP), T2DM rats given the diet of combination of black soybean and purple sweet potato with the ratio of $1: 3,2: 2$, and $3: 1$, respectively (DM $+\mathrm{C} 1-$ 3). The dose of $0.6 \mathrm{mg} / \mathrm{kg} \mathrm{BW}$ glibenclamide was chosen based on the previous reports ${ }^{22}$. The diet of BSB and PSP was given for 30 days (30 g/day for each rat). At the end of treatment, the rats were fasted overnight and sacrificed by anaesthesia following dislocation. 


\section{Sperm count and motility assessment}

Cauda epididymis of rats was taken and put into a Petri dish containing $1 \mathrm{ml}$ of $\mathrm{NaCl} 0.9 \%$ solution, then minced using a scalpel. The sperm count was carried out using a Neubauer (height of $1 / 10 \mathrm{~mm}$, Assistant, Germany) haemacytometer. The sperm count was performed manually using a light microscope (Olympus, Japan) following WHO standards (2010). The result of sperm count was reported as the number of counted sperm $/ \mathrm{ml}$. The motility was observed using a spermatozoa suspension dropped once onto the object glass and then examined under a microscope with $100 \times$ magnification. The motility was determined by calculating the number of spermatozoa that either moved or did not move at all per 100 spermatozoa in ten visual fields ${ }^{23}$. The motility of spermatozoa was shown as the percentage of motile sperms relative to the total counted sperms.

\section{Sperm viability and abnormality}

The ratio of live and died sperm was determined using 1\% eosin and 10\% nigrosin. One hundred sperms were counted on each slide, and the results of calculation were reported as the percentage of live sperms. Red coloured-sperms were categorized as dead sperms, while the uncolored sperms were categorized as alive. Abnormality at the head, centre part, and tail of the sperms were determined through observation of 100 sperms per rat in five different slides. The morphology of sperm was examined using a light microscope (Olympus, CX23, Tokyo) with $400 \times$ magnification. The abnormality data are the number of abnormal sperms compared to the total counted sperms.

\section{Histological examination}

Testicle were taken, weighed, washed with a buffer solution, and stored in $10 \%$ formalin. A preparation made to examine the testicle using the IHC-Fluorescence technique for examination ROS production was performed using c-ROS (Bioss) as a primary antibody following with goat anti-Rat IgG-FITC (sc-2011: Santa Cruz) as a secondary antibody. The preparation was observed using a fluorescence microscope (Olympus IX81) connected to Software Olympus Flouview with $400 \times$ magnification with the ROS production counted based on intensity $/ \mathrm{mm}^{2}$ in the testicle.

\section{Hormone measurement}

Blood was taken from the heart and then left for $30 \mathrm{~min}$ then centrifuged at $1500 \times \mathrm{g}$ for $15 \mathrm{~min}$ to isolate the serum. The blood serum was stored at $-20^{\circ} \mathrm{C}$ until used. The testosterone content was measured using the ELISA technique, and its absorbance was measured at $450 \mathrm{~nm}$ following the protocol provided with the assay kit (E-EL-0072: Elabscience).

\section{Statistical analysis}

Data were analysed using one-way ANOVA with EXCEL. If significance $(p<0.05)$ was observed, the data was examined using Duncan's multiple range test (DMRT). The data are presented as mean \pm SD.

\section{RESULTS}

\section{Combination of PSP and BSB normalizes the glucose level in the T2DM rat model}

The results of our analysis indicate a difference in glucose content between the T2DM rat model compared to the control $(p<0.05)$ (Table 1$)$. The T2DM rat model exhibited an increase in glucose content, while the treatment of PSP, BSB, and the combination of both could decrease the glucose levels (Table 1). Interestingly, treatment with PSP in the T2DM rat model produced lowered testicle weight and epididymis compared to the other treatment groups. Testosterone content significantly increased after treatment using BSB as well as with the combination containing a high ratio of BSB to PSP (Table 1).

\section{Combination of PSP and BSB restores the seminiferous tubules diameter and suppresses the ROS expression in tubules seminiferous of testicle of T2DM rat model}

Our results indicate that there is a difference in the diameter of the seminiferous tubules and ROS intensity in seminiferous tubules in testicles of T2DM rat model compared to the control $(p<0.05)$ (Fig. 1ab). The T2DM rat model underwent a decrease in seminiferous tubules diameter (Fig. 1c) and an increase in ROS (Fig. 1d), while the treatment of PSP and BSB could restore the diameter of the seminiferous tubules and decrease the ROS production. The combination of BSB and PSP (1:3) could suppress the production of ROS in the testicle, although the effect was not different from the normal rat group (Fig. 1d). Glibenclamide treatment $(0.6 \mathrm{mg} / \mathrm{kg})$ given to T2DM rats did not alter production of ROS 
Table 1 Contents of blood glucose, weight of testicle, weight of epididymis, and testosterone level of T2DM rats with/without treatment using the BSB and PSP.

\begin{tabular}{lccccc}
\hline & $\begin{array}{c}\text { Initial glucose } \\
(\mathrm{mg} / \mathrm{dl})\end{array}$ & $\begin{array}{c}\text { Final glucose } \\
(\mathrm{mg} / \mathrm{dl})\end{array}$ & $\begin{array}{c}\text { Testicle } \\
(\mathrm{g})\end{array}$ & $\begin{array}{c}\text { Epididymis } \\
(\mathrm{g})\end{array}$ & $\begin{array}{c}\text { Testosterone } \\
(\mathrm{pg} / \mathrm{dl})\end{array}$ \\
\hline $\mathrm{N}$ & $72 \pm 4.6^{\mathrm{a}}$ & $82 \pm 2.5^{\mathrm{a}}$ & $10.53 \pm 1.55^{\mathrm{cd}}$ & $2.07 \pm 0.12^{\mathrm{c}}$ & $1.50 \pm 0.28^{\mathrm{b}}$ \\
$\mathrm{DM}$ & $360 \pm 86.1^{\mathrm{b}}$ & $370 \pm 58.4^{\mathrm{b}}$ & $8.17 \pm 0.72^{\mathrm{b}}$ & $1.73 \pm 0.58^{\mathrm{c}}$ & $0.31 \pm 0.06^{\mathrm{a}}$ \\
$\mathrm{DM}+\mathrm{Glb}$ & $388 \pm 66.5^{\mathrm{b}}$ & $98 \pm 21.1^{\mathrm{a}}$ & $8.65 \pm 1.44^{\mathrm{bcd}}$ & $1.78 \pm 0.03^{\mathrm{c}}$ & $1.55 \pm 0.21^{\mathrm{b}}$ \\
$\mathrm{DM}+\mathrm{BSB}$ & $323 \pm 32.7^{\mathrm{b}}$ & $90 \pm 16.6^{\mathrm{a}}$ & $9.75 \pm 1.86^{\mathrm{bcd}}$ & $1.55 \pm 0.28^{\mathrm{bc}}$ & $3.47 \pm 0.01^{\mathrm{c}}$ \\
$\mathrm{DM}+$ PSP & $329 \pm 44.6^{\mathrm{b}}$ & $89 \pm 4.4^{\mathrm{a}}$ & $5.25 \pm 0.79^{\mathrm{a}}$ & $1.02 \pm 0.14^{\mathrm{a}}$ & $1.38 \pm 0.40^{\mathrm{b}}$ \\
$\mathrm{DM}+\mathrm{C} 1$ & $336 \pm 114.5^{\mathrm{b}}$ & $84 \pm 2.5^{\mathrm{a}}$ & $8.40 \pm 1.23^{\mathrm{bc}}$ & $1.13 \pm 0.13^{\mathrm{ab}}$ & $1.36 \pm 0.39^{\mathrm{b}}$ \\
$\mathrm{DM}+\mathrm{C} 2$ & $287 \pm 103.5^{\mathrm{b}}$ & $92 \pm 3.1^{\mathrm{a}}$ & $10.50 \pm 0.15^{\mathrm{cd}}$ & $1.72 \pm 0.35^{\mathrm{c}}$ & $4.52 \pm 0.43^{\mathrm{d}}$ \\
$\mathrm{DM}+\mathrm{C} 3$ & $334 \pm 125.0^{\mathrm{b}}$ & $94 \pm 3.0^{\mathrm{a}}$ & $10.93 \pm 1.03^{\mathrm{d}}$ & $1.88 \pm 0.21^{\mathrm{c}}$ & $3.48 \pm 0.01^{\mathrm{c}}$ \\
\hline
\end{tabular}

Different notation shows that there is a significant difference $(p<0.05)$ based on the DMRT.

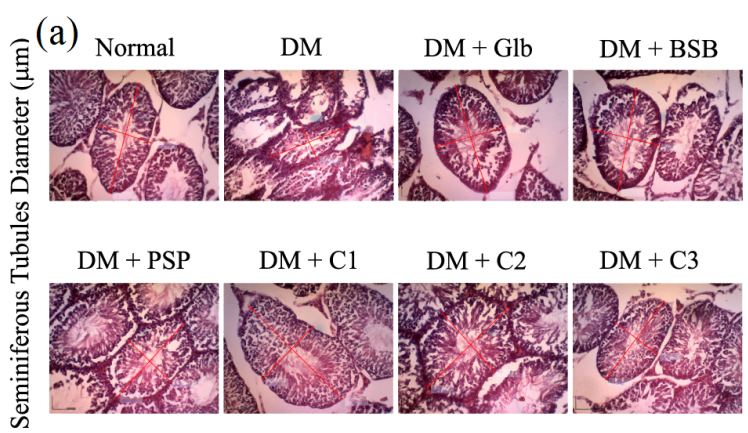

(c)

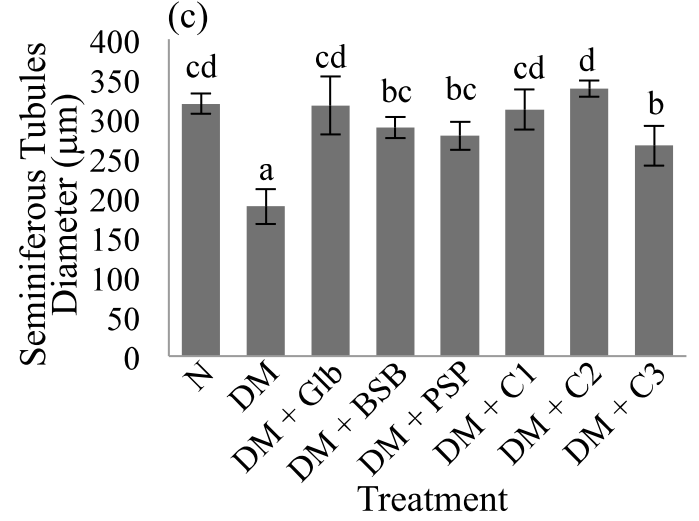

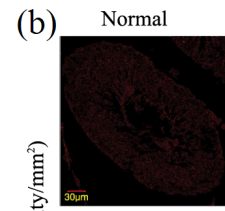

DM+PSP
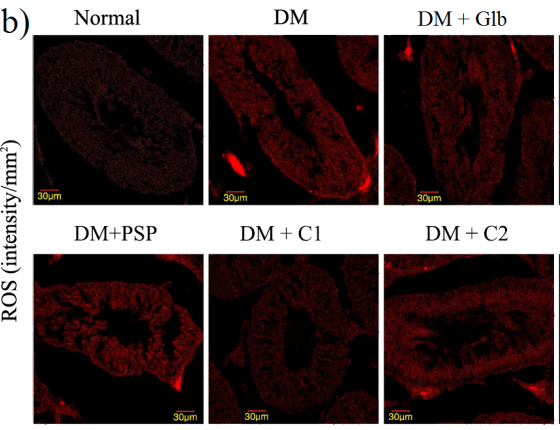

$\mathrm{DM}+\mathrm{BSB}$

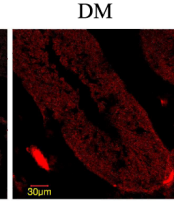

$\mathrm{DM}+\mathrm{C} 2$

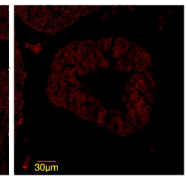

$\mathrm{DM}+\mathrm{C} 3$

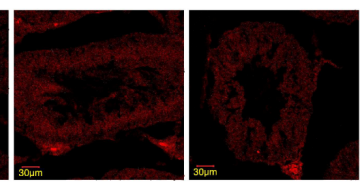

(d)

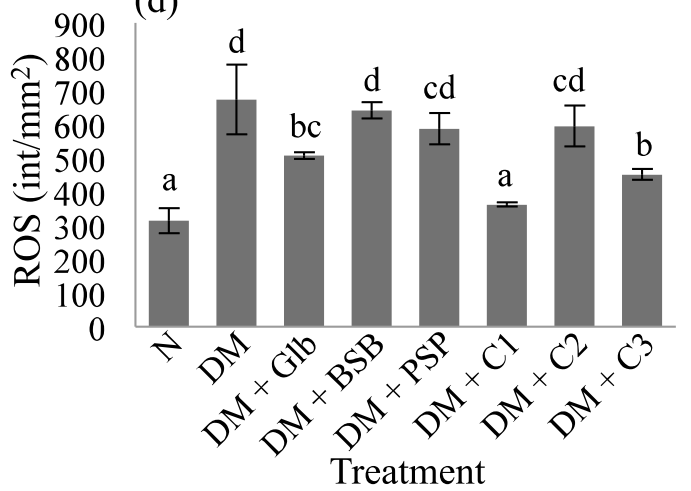

Fig. 1 The treatment using only BSB and the combination of BSB and PSP could suppress the production of ROS in the testicle. (a) cross-section of testicle with HE staining at $400 \times$ magnification. (b) cross-section of testicle with IHC-Fluorescence staining at $400 \times$ magnification. (c) seminiferous tubules diameter represented as the mean $\pm S D$, and (d) ROS intensity in the testicle represented as the mean \pm SD. The different notation showed that there was a significant difference $(p<0.05)$ based on of DMRT.

compared to treatment with BSB and PSP (3:1) (Fig. 1d).

\section{Combination of PSP and BSB improves the sperm quality of T2DM rat model}

A significant difference in concentration, motility, abnormality, and viability of spermatozoa of T2DM model-rats was observed compared to the control animals (Fig. 2a-d). The T2DM Rat model exhib- 


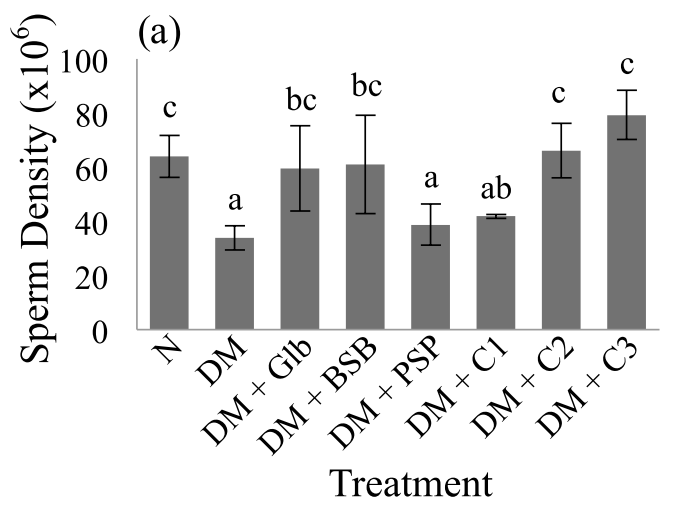

(c)

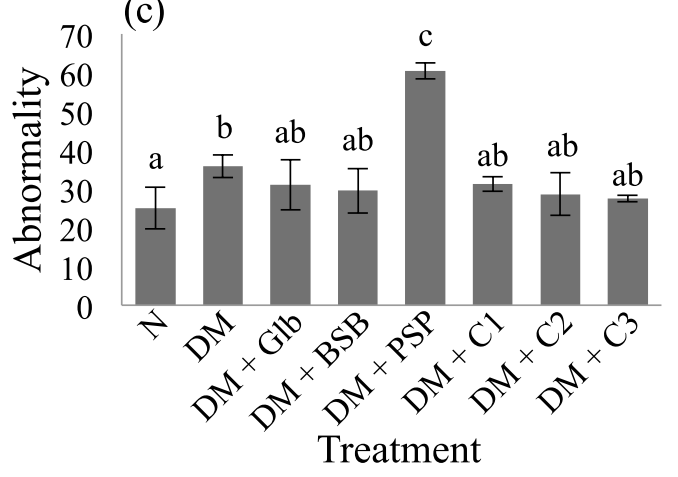

(b)

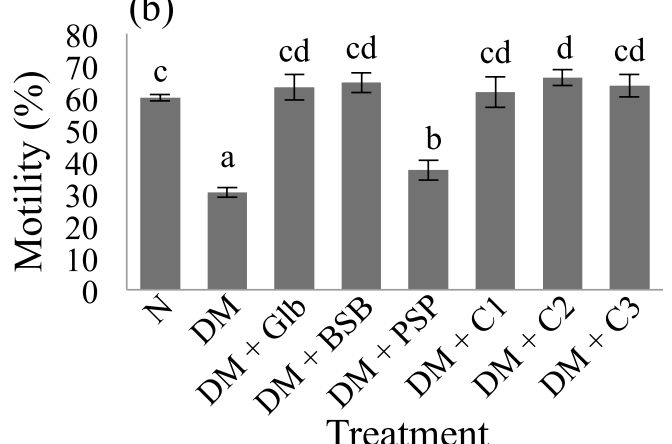

(d)

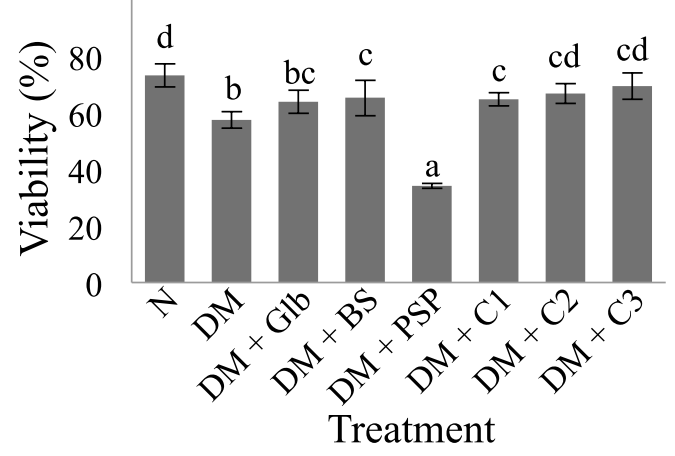

Fig. 2 Treatment using only BSB or the combination of BSB and PSP could repair the sperm quality. (a) the sperm concentration, (b) sperm motility, (c) sperm abnormality, and (d) sperm viability. The data were represented as the mean \pm SD. The different notation indicated that there was a significant difference $(p<0.05)$ based on DMRT.

ited a decrease in concentration, motility, and viability of spermatozoa. Interestingly, the sweet potato diet did not generate a significant difference in terms of concentration and viability of spermatozoa compared to the T2DM group. The abnormality of spermatozoa significantly increased with treatment of PSP only. The combination of PSP at the higher ratio than that of BSB also did not produce any effect that showed significant difference compared to T2DM group only. However, when BSB was given at the same ratio $(2: 2)$ or in excess (3:1) compared to the PSP, significant repair in terms of concentration, motility, abnormality, and viability of spermatozoa was observed in T2DM rats (Fig. 2).

\section{DISCUSSION}

Hyperglycaemia causes oxidative stress due to the overproduction of $\mathrm{ROS}^{24}$. The overproduction of ROS increases the permeability of mitochondria membrane, disrupts the respiration system, and impairs production of ATP. In addition, loss of mitochondrial function decreases axonemal protein phosphorylation which can influence the sperm quality $^{25}$. Most organisms contain a system to detoxify the overproduction of ROS ${ }^{26}$. However, addition of an exogenous antioxidant is needed to help neutralize ROS in some disease states ${ }^{27}$. The use of an antioxidant to reduce ROS may prevent the development of T2DM. Natural materials that are rich sources of antioxidants are $\mathrm{BSB}^{16}$ and $\mathrm{PSP}^{28}$. However, the health benefits of the combination of BSB and PSP to the function of male reproduction has not been examined.

The results presented here demonstrate that treatment using PSP, BSB, and the combination of both could normalize blood glucose levels in the DM group. BSB has strong antioxidant activity in all parts of its seed ${ }^{16}$. Phytoestrogen diets using soybean could increase the sensitivity of insulin 
by modulating glucose metabolic enzymes through AMPK activation ${ }^{29}$. In addition, the hull of BSB seed is rich in anthocyanin (cyanidin 3-glucoside; C3G) and procyanidin that may reduce the hyperglycaemia condition found in T2DM rat model through up-regulation of GLUT4 in muscle tissue and downregulation of gluconeogenesis in liver ${ }^{30,31}$. PSP can restore glucose metabolism and $\beta$ cells of the pancreas of rats induced with alloxan ${ }^{32}$. The disorder of insulin sensitivity will cause impact spermatogenesis since insulin also exhibits metabolic cooperation with testicular cells ${ }^{33}$. Preventing insulin sensitivity is significant for the support of normal spermatogenesis $^{34}$.

We observed a significant increase of ROS production in the DM-rat model (Fig. 2b). Treatment of BSB and PSP individually or in combination could reduce ROS production in the testicle. Anthocyanin of the BSB suppresses the production of malondialdehyde (MDA) aiding superoxide dismutase (SOD) and catalase as the antioxidant enzymes of the DM-rat model ${ }^{35}$. Previous reports have shown anthocyanin of PSP reduces accumulation of free radicals and ROS content in the hypothalamus of rats given high-fat $\operatorname{diet}^{36}$. Our analysis demonstrated that the ROS intensity decreased to levels similar to the normal group when BSB and PSP were given simultaneously. This effect may be due to the phytochemicals contained in both materials working in synergy to detoxify free radicals and ROS.

Our results also demonstrated that the sperm quality in the DM-rat model was decreased compared to healthy rats. Treatment using only BSB or the combination with PSP could restore sperm quality. The decreased quality of sperms in the DM rat group appeared to be caused by increased in ROS production. This stimulation of oxidative stress may influence the apoptosis of progenitor cells reducing sperm quality during spermatogenesis ${ }^{10}$. Based on the results presented here, the decrease in the content of ROS was followed by the repair of the sperm quality. The high content of antioxidants in BSB and PSP is proposed to protect the sperms from the attack of free radicals, increasing sperm quality. In addition, giving antioxidants could protect spermatozoa DNA from free radicals and enhance the stability of testicle barrier ${ }^{37}$.

Soybean is a rich source of amino acids that functions to provide energy for sperm cells, recover and improve the spermatozoa density, and protect the spermatozoa from lipid peroxidation ${ }^{38}$. Daidzein compound from BSB is thought to modulate the expression of steroidogenic compounds to improve the synthesis of testosterone ${ }^{39}$. Meanwhile, the PSP contains caffeic acid that can stimulate the synthesis of testosterone ${ }^{15}$. Testosterone can stimulate and regulate the process of spermatogenesis and sperm maturation. However, the treatment using only PSP could not restore the quality of spermatozoa. Recent evidence indicates that there was no change in sperm parameters from the rats treated using sweet potato ${ }^{40}$. Based on these results, the sperm quality would improve only when the PSP and BSB were given. The mechanism of action of PSP on sperm quality of DM rats remains unclear and further research should be conducted to better understand the role of PSP on the fertility of DM individuals.

Acknowledgements: This research was funded by the Ministry of Research, Technology, and Higher Education, research contract number 3.4.8/UN32.14/LT/2017.

\section{REFERENCES}

1. International Diabetes Federation (2015) Idf Diabetes Atlas, 7th edn, International Diabetes Federation.

2. Matthews DR, Matthews PC (2011) Banting memorial lecture 2010. Type 2 diabetes as an 'infectious' disease: is this the black death of the 21st century? Diabet Med 28, 2-9.

3. Rasmi Y, Golizadeh M, Valizadeh N, SalehMoghaddam M (2014) Systemic low-grade inflammation in siblings of type 2 diabetic patients. ScienceAsia 40, 285-9.

4. Tiwari AK, Rao JM (2002) Diabetes mellitus and multiple therapeutic approaches of phytochemicals: Present status and future prospects. Curr Sci 83, 30-8.

5. Amaral S, Oliveira PJ, Ramalho-santos J (2008) Diabetes and the impairment of reproductive function: possible role of mitochondria and reactive oxygen species. Curr Diabetes Rev 4, 46-54.

6. La Vignera S, Condorelli R, Vicari E, D'Agata R, Calogero AE (2012) Diabetes mellitus and sperm parameters. J Androl 33, 145-53.

7. Wellen KE, Thompson CB (2010) Cellular metabolic stress: considering how cells respond to nutrient excess. Mol Cell 40, 323-32.

8. Rahimi-Madiseh M, Malekpour-Tehrani A, Bahmani M, Rafieian-Kopaei M (2016) The research and development on the antioxidants in prevention of diabetic complications. Asian Pac J Trop Med 9, 825-31.

9. Gil-Guzman E, Ollero M, Lopez M, Sharma R, Alvarez J, Thomas A, Agarwal A (2001) Differential production of reactive oxygen species by subsets of human spermatozoa at different stages of maturation. Hum Reprod 16, 1922-30.

10. Aziz N, Saleh RA, Sharma RK, Lewis-Jones I, Esfandiari N, Thomas AJ, Agarwal A (2004) Novel 
association between sperm reactive oxygen species production, sperm morphological defects, and the sperm deformity index. Fertil Steril 81, 349-54.

11. Waramboi JG, Dennien S, Gidley MJ, Sopade PA (2011) Characterisation of sweetpotato from Papua New Guinea and Australia: Physicochemical, pasting and gelatinisation properties. Food Chem 126, 1759-70.

12. Kano M, Takayanagi T, Harada K, Makino K, Ishikawa F (2005) Antioxidative activity of anthocyanins from purple sweet potato, Ipomoera batatas Cultivar Ayamurasaki. Biosci Biotechnol Biochem 69, 979-88.

13. Wang S, Nie S, Zhu F (2016) Chemical constituents and health effects of sweet potato. Food Res Int 89, 90-116.

14. Maharani T, Sargowo D (2012) Anthocyanin effect from purple Ipomoea Batatas decrease formation. Int J Sci Technol 1, 9-15.

15. Adienbo OM, Wodu CO (2015) Fertility-enhancing potentials of Ipomoea batatas (sweet potato) in male Albino Wistar rats. Eur J Biomed Pharm Sci 2, 1197-202.

16. Xu B, Chang SKC (2008) Antioxidant capacity of seed coat, Dehulled bean, and whole black soybeans in relation to their distributions of total phenolics, phenolic acids, anthocyanins, and isoflavones. J Agric Food Chem 56, 8365-73.

17. Dajanta K, Chukeatirote E, Apichartsrangkoon A, Frazier RA (2009) Enhanced aglycone production of fermented soybean products by Bacillus species. Acta Biol Szeged 53, 93-8.

18. Okazaki Y, Iqbal M, Kawakami N, Yamamoto Y, Toyokuni S, Okada S (2010) A beverage containing fermented black soybean ameliorates ferric nitrilotriacetate-induced renal oxidative damage in rats. J Clin Biochem Nutr 47, 198-207.

19. Gofur A, Lestari SR (2016) Effect of black soybean natto extract (Glycine soja) on reproduction system of hypercholesterolemia male mice. Asian Pacific $J$ Reprod 5, 387-90.

20. Lestari SR, Djati MS, Rudijanto A, Fatchiyah F (2015) PPAR $\gamma$ expression by rambutan peel extract in obesity rat model-induced high-calorie diet. Asian Pac $J$ Trop Biomed 5, 852-7.

21. Zhang M, Lv XY, Li J, Xu ZG, Chen L (2008) The characterization of high-fat diet and multiple low-dose streptozotocin induced type 2 diabetes rat model. Exp Diabetes Res 2008, 1-9.

22. Kulkarni YA, Veeranjaneyulu A (2013) Effects of Gmelina arborea extract on experimentally induced diabetes. Asian Pac J Trop Med 6, 602-8.

23. WHO (2010) WHO Laboratory Manual for the Examination and Processing of Human Semen, 5th edn, Geneva.

24. Brownlee M (2001) Biology of diabetic complications. Nature 414, 813-20.

25. O’Flaherty C, de Lamirande E, Gagnon C (2006) Pos- itive role of reactive oxygen species in mammalian sperm capacitation: triggering and modulation of phosphorylation events. Free Radic Biol Med 41, 528-40.

26. Dias TR, Tomas G, Teixeira NF, Oliveira PF, Silva BM (2013) White tea (Camellia sinensis (L.)): antioxidant properties and beneficial health effects. Int $J$ Food Sci Nutr Diet 2, 19-26.

27. Valko M, Morris H, Cronin M (2005) Metals, toxicity and oxidative stress. Curr Med Chem 12, 1161-208.

28. Rumbaoa RGO, Cornago DF, Geronimo IM (2009) Phenolic content and antioxidant capacity of Philippine sweet potato (Ipomoea batatas) varieties. Food Chem 113, 1133-8.

29. Cederroth CR, Vinciguerra M, Gjinovci A, Kühne F, Klein M, Cederroth M, Caille D, Suter M, et al (2008) Dietary phytoestrogens activate AMP-activated protein kinase with improvement in lipid and glucose metabolism. Diabetes 57, 1176-85.

30. Kurimoto Y, Shibayama Y, Inoue S, Soga M, Takikawa M, Ito C, Nanba F, Yoshida T, et al (2013) Black soybean seed coat extract ameliorates hyperglycemia and insulin sensitivity via the activation of AMPactivated protein kinase in diabetic mice. J Agric Food Chem 61, 5558-64.

31. Tantipaiboonwong P, Pintha K, Chaiwangyen W, Chewonarin T, Pangjit K, Chumphukam O, Kangwan N, Suttajit M (2017) Anti-hyperglycaemic and anti-hyperlipidaemic effects of black and red rice in streptozotocin-induced diabetic rats. ScienceAsia 43, 281-8.

32. Wicaksono LA, Yunianta, Widyaningsih TD (2016) Anthocyanin extraction from purple sweet potato cultivar antin-3 (Ipomoea batatas L.) using maceration, microwave assisted extraction, ultrasonic assisted extraction and their application as antihyperglycemic agents in alloxan-induced wistar rats. Int J PharmTech Res 9, 181-92.

33. Oliveira PF, Alves MG, Rato L, Laurentino S, Silva J, Sá R, Barros A, Sousa M, et al (2012) Effect of insulin deprivation on metabolism and metabolismassociated gene transcript levels of in vitro cultured human Sertoli cells. Biochim Biophys Acta - Gen Subj 1820, 84-9.

34. Alves MG, Rato L, Carvalho RA, Moreira PI, Socorro S, Oliveira PF (2013) Hormonal control of Sertoli cell metabolism regulates spermatogenesis. Cell Mol Life Sci 70, 777-93.

35. Nizamutdinova IT, Jin YC, Chung J, Shin SC, Lee SJ, Seo HG, Lee JH, Chang KC, Kim HJ (2009) The antidiabetic effect of anthocyanins in streptozotocininduced diabetic rats through glucose transporter 4 regulation and prevention of insulin resistance and pancreatic apoptosis. Mol Nutr Food Res 53, 1419-29.

36. Zhang Y, Niu F, Sun J, Xu F, Yue R (2015) Purple sweet potato (Ipomoea batatas L.) color alleviates high-fat-diet-induced obesity in SD rat by mediating 
leptin's effect and attenuating oxidative stress. Food Sci Biotechnol 24, 1523-32.

37. Jedlinska-Krakowska M, Bomba G, Jakubowski K, Rotkiewicz T, Jana B, Penkowski A (2006) Impact of oxidative stress and supplementation with vitamins $\mathrm{E}$ and C on testes morphology in rats. $J$ Reprod Dev 52, 203-9.

38. Srivastava S, Desai P, Coutinho E, Govil G (2006) Mechanism of action of L-arginine on the vitality of spermatozoa is primarily through increased biosynthesis of nitric oxide. Biol Reprod 74, 954-8.

39. Zhang L, Cui S (2009) Effects of Daidzein on testosterone synthesis and secretion in cultured mouse Leydig cells. Asian-Aust J Anim Sci 22, 618-25.

40. Ekpo PB, Uno UU, Ogbe HO, Ekaluo UB (2017) Effect of sweet potato (Ipomoea batatas) tuber on sperm profile and testicular integrity of male albino rats. Arch Curr Res Int 9, 1-7. 